\title{
UPAYA PENINGKATAN CAKUPAN PENJARINGAN KESEHATAN ANAK SEKOLAH SISWA SD SEDERAJAT DI DESA MENDALO INDAH KECAMATAN JAMBI LUAR KOTA KABUPATEN MUARO JAMBI
}

\author{
Willia Novita Eka Rini ${ }^{1}$, Rumita Ena Sari ${ }^{2}$ \\ Program Studi Kesehatan Masyarakat Fakultas Kesehatan Masyarakat \\ Universitas Jambi \\ Email: willia_novita.er@unja.ac.id
}

\begin{abstract}
ABSTRAK
Kecamatan Jambi Luar Kota merupakan salah satu kecamatan di Kabupaten Muaro Jambi, cakupan penjaringan kesehatan anak sekolah di wilayah kerja Puskesmas Sungai Duren Kecamatan Jambi Luar Kota Tahun 2015 masih sangat rendah. Dari jumlah siswa SD sederajat sebanyak 701 orang yang mendapat pelayanan penjaringan terendah terdapat di desa Mendalo Indah yaitu sebesar 29,1\% atau sekitar 32 orang siswa, sehingga perlu upaya serius dalam peningkatan cakupan penjaringan kesehatan anak sekolah SD sederajat. Berbagai upaya telah dilakukan dalam pemberian informasi melalui penyuluhan ke sekolah-sekolah, pemeriksaan kesehatan, usaha kesehatan sekolah, sosialisasi buku KIA, tetapi belum maksimal, sehingga perlu langkah nyata untuk meningkatkan cakupan penjaringan kesehatan anak sekolah siswa SD sederajat, yaitu dengan melibatkan secara komprehensif guru, tenaga kesehatan, tokoh masyarakat, termasuk aparat desa dan seluruh bidan desa dan pimpinan puskesmas. Berdasarkan analisis situasi tersebut maka dicarikan solusi melalui kegiatan KKN bagi mahasiswa Universitas Jambi, dengan pertimbangan mahasiswa akan mampu melaksanakan kegiatan secara langsung di masyarakat.Metode yang akan dilakukan dalam kegiatan pengabdian ini adalah: kunjungan ke seluruh sekolah yang berada di wilayah desa Mendalo Indah dengan melakukan pendampingan atau sweeping dengan melibatkan guru, kader kesehatan, petugas puskesmas, memberikan penyuluhan-penyuluhan tentang kesehatan, mengaktifkan kader-kader kesehatan dimasyarakat maupun di sekolah, mengadakan pemeriksaan kesehatan anak sekolah, pemeriksaan yang dilakukan seperti: pemeriksaan gizi, pemeriksaan kebersihan diri, pemeriksaan mata, pemeriksaan pendengaran, pemeriksaan gigi dan mulut, dan pemeriksaan kebugaran jasmani. Hasil yang diperoleh dari kegiatanKKNPPM ini anatara lain: tersosialisasi materi-materi tentang kesehatan, prilaku hidup bersih dan sehat, serta penyakit-penyakit seperti DBD, diare, cara mencuci tangan dan menyikat gigi yang baik dan benar, terlatihnya kader kesehatan disekolah yang terdiri dari siswa sebagai dokter kecil dan guru sebagai penanggung jawab UKS, bertambahnya keaktifan kader posyandu, meningkatnya data penjaringan kesehatan menjadi 93,3\%, diperolehnya media promosi (buku saku, Leaflet, poster \& banner).
\end{abstract}

\section{Kata Kunci : Kesehatan Anak Sekolah, Kkn-Ppm, Peran Nyata Mahasiswa}

\section{PENDAHULUAN}

Pembangunan pedesaan merupakan bagian dari pembangunan nasional seperti yang diamanatkan oleh Undang-Undang Dasar 1945 dan GBHN. Dalam proses pembangunan nasional memerlukan partisipasi aktif dari seluruh lapisan masyarakat termasuk dalam hal ini pemerintah, perguruan tinggi dan masyarakat. 
Dalam hal peran serta perguruan tinggi pada pembangunan nasional, perguruan tinggi menurunkan mahasiswa dalam bentuk Kuliah Kerja Nyata (KUKERTA), hal ini didasari oleh salah satu isi dari Tri Darma Perguruan Tinggi yaitu "Pengabdian Kepada Masyarakat". Berdasarkan padahal di atas, mahasiswa sebagai kaum intelektual yang memiliki kesempatan belajar di perguruan tinggi perlu mengimplementasikan ilmu yang dipelajarinya secara disipliner. Kuliah Kerja Nyata (KUKERTA) memiliki rencana program-program yang sesuai dengan kebutuhan dan kondisi nyata yang ada pada masyarakat pedesaan, dengan demikian pembangunan pedesaan yang diharapkan mampu terwujud sehingga dapat mencapai masyarakat adil dan makmur.

Ada berbagai macam alternatif dalam pemecahan masalah yang timbul di daerah pedesaan, semua alternatif tersebut diwujudkan dalam bentuk realisasi program kerja oleh mahasiswa KUKERTA yang pada intinya menyalurkan aspirasi, saran, pendapat dan melihat kondisi teknis serta non teknis di tengah kehidupan masyarakat.

Puskesmas Sungai Duren merupakan salah satu puskesmas strategis di Kabupaten Muaro Jambi dengan jumlah penduduk 37.108 jiwa, dan memiliki wilayah kerja 1 kelurahan dan 8 desa. Pada tahun 2015siswa yang mendapatkan pelayanan penjaringan kesehatan anak sekolah SD sederajat sebanyak 576 dari 701 jumlah siswa (82,1\%), meskipun secara cakupan sudah bagus, tetapi masih belum sesuai dengan target yang ditetapkan yaitu $100 \%$ dalam arti semua siswa harus mendapatkan layanan penjaringan kesehatan anak sekolah, karena anak merupakan asset masa depan suatu bangsa.

Penjaringan kesehatan peserta didik merupakan salah satu indikator standar pelayanan minimal bidang kesehatan.Penjaringankesehatan bertujuan untuk meningkatkan status kesehatan peserta didik.Anak usia sekolah merupakan sasaran strategis untuk pelaksanaan program kesehatan, selain jumlahnya yang besar ( $30 \%$ ) dari jumlah penduduk, mereka juga merupakan sasaran yang mudah dijangkau karena terorganisir dengan baik. Dari beberapa penelitian diketahui bahwa sebagian anak SD/MI masih mengalami masalah gizi yang cukup serius, dan prevalensi kecacingan pada cukup tinggi, serta kesehatan gigi dan kesehatan indera penglihatan dan pendengaran masih ditemukan.Melihat permasalahan diatas, pelayanan kesehatan di sekolah diutamakan pada upaya peningkatan kesehatan.Kurangnya cakupan penjaringan maka perlu diadakan program untuk peningkatan cakupan penjaringan terutama pada Sekolah Dasar sederajat yang ada di Desa Mendalo Indah.

Menindaklanjuti program Kementrian Kesehatan keluarga sehat untuk mewujudkan Indonesia sehat 2020 dalam upaya peningkatan cakupan pelayanan penjaringan kesehatan, maka yang perlu mendapatkan perhatian adalah Desa Mendalo Indah karena baru 32 siswa $(29,1 \%)$. Kenyataan menunjukkan bahwa rendahnya cakupan pelayanan penjaringan kesehatan anak sekolah belum menunjukkan target yang telah ditentukan karena 2 hal yaitu dari faktor keluarga (tingkat sosial ekonomi, akses, kepedulian keluarga, tingkat pendidikan, dll) dan faktor layanan petugas kesehatan (tenaga, sarana dan prasarana, program kesehatan terkini, keberlangsungan program kesehatan anak).

Berbagai upaya telah dilakukan terutama dalam pelaksanaan program-program kesehatan melalui pertemuan di posyandu, layanan kesehatan anak sekolah, usaha kesehatan sekolah, sekolah sehat, tetapi belum maksimal, sehingga pengusul dan mitra (Puskesmas Sungai Duren) berkolaborasi untuk penyelesaian peningkatan upaya cakupan penjaringan kesehatan 
Jurnal Karya Abdi Masyarakat

Volume 2 Nomor 1 Januari - Juni 2018

anak sekolahyang melibatkan secara komprehensif sekolah, kader UKS, guru, kepala sekolah, tokoh agama, tokoh masyarakat, termasuk aparat desa dan pimpinan puskesmas beserta staf.

\section{Isi}

Kuliah Kerja Nyata merupakan salah satu bentuk kegiatan yang memberikan pengalaman belajar kepada mahasiswa untuk hidup di tengah-tengah masyarakat, sekaligus sebagai proses pembelajaran serta mengabdi kepada masyarakat yang sedang membangun dan secara langsung mengidentifikasi serta membantu menangani masalah-masalah pembangunan yang sedang dihadapi. Kegiatan KUKERTA mengajak mahasiswa untuk ikut serta mengamati, menganalisis, menarik kesimpulan dan memberikan solusi-solusi yang didapat dari data dan situasi wilayah kerja.

Program kerja yang dilaksanakan dalam Kuliah Kerja Nyata diharapkan relevan dengan kebutuhan masyarakat tempat dimana peserta ditempatkan. Oleh karena itu, perlu dilakukan observasi lapangan tentang permasalahan yang sesungguhnya dialami masyarakat setempat agar tidak terjadi kesalahan dalam program kerja atau melaksanakan program kerja yang tidak sesuai dengan kondisi masyarakat setempat.

Upaya yang dirancang dalam kegiatan pengabdian masyarakat ini sebagai berikut:

1. Identifikasi masalah, mahasiswa di bagi 4 kelompok untuk melakukan identifikasi masalah dan sampai sejauh mana tingkat urgensi masalah tersebut yang didukung sumber data / informasi yang akurat.

2. Memilih masalah prioritas, masing-masing kelompok melakukan pemilihan masalah yang merupakan masalah prioritas.

3. Analisis penyebab masalah, masing-masing kelompok melakukan analisis penyebab utama masalah yang terjadi dengan mempertimbangkan kekuatan/sumber daya.

4. Menetapkan penyebab utama, harus mendapatkan kunci yang menjadi penyebab utama dari permasalahan yang terjadi di masyarakat.

5. Mencari solusi potensial, masing-masing kelompok melakukan identifikasi solusi yang mempunyai efek domino terhadap permasalahan yang terjadi di masyarakat.

6. Memilih dan perencanaan solusi, pertimbangkan kekuatan sumber daya baik internal maupun eksternal dalam penyelesaian masalah

7. Pelaksanaan, masing-masing kelompok melakukan aksinya sesuai dengan POA yang sudah disusun.

8. Evaluasi, masing-masing kelompok melakukan evaluasi secara berkala baik input, proses dan output, termasuk evaluasi dampak.

\section{METODE PELAKSANAAN}

Metode yang akan dilakukan dalam kegiatan pengabdian ini adalah :

1. Kunjungan ke seluruh sekolah yang berada di wilayah desa Mendalo Indah dengan melakukan pendampingan atau sweeping dengan melibatkan guru, kader kesehatan, petugas puskesmas.

2. Memberikan penyuluhan-penyuluhan tentang kesehatan.

3. Mengaktifkan kader-kader kesehatan dimasyarakat maupun di sekolah. 
4. Mengadakan pemeriksaan kesehatan anak sekolah, pemeriksaan yang dilakukan seperti: pemeriksaan gizi, pemeriksaan kebersihan diri, pemeriksaan mata, pemeriksaan pendengaran, pemeriksaan gigi dan mulut, pemeriksaan kebugaran jasmani.

\section{HASIL YANG DICAPAI}

\section{Pengaktifan UKS Melalui Pelatihan Dokter Kecil Dan Guru UKS}

Kegiatan ini dilaksanakan dengan tujuan untuk mengingkatkan kesadaran dan upaya penjaringan kesehatan siswa SD sederajat melalui Usaha Kesehatan Sekolah (UKS) dan Dokter Kecil sebagai kader kesehatan yang ada di sekolah.Adapun dokter kecil merupakan siswa yang memenuhi kriteria dan telah terlatih untuk ikut melaksanakan sebagian usaha pemeliharaan dan peningkatan kesehatan terhadap diri sendiri, teman, keluarga, dan lingkungan sekitarnya. Dokter kecil dapat meningkatkan upaya pentingnya kesadaran akan kesehatan paling minimal untuk kesehatan diri pribadi.

Diharapkan melalui kegiatan ini, terjadi peningkatan kedasaran kesehatan dan cakupan penjaringan kesehatan di sekolah dasar serta diharapkan nantinya ada keberlanjutan dalam upaya peningkatan penjaringan kesehatan siswa SD dengan siswa itu sendiri yang berperan sebagai motor penggeraknya dibantu dengan pihak sekolah tentunya.

Pengaktifan dan pelatihan dalam bidang kesehatan bertujuan untuk meningkatkan pengetahuan dan keterampilan dalam bidang kesehatan.Pelatihan dokter kecil sangat baik sekali untuk anak-anak, karena mempraktikan perilaku hidup bersih dan sehat sejak dini. Pembangunan kesehatan kini dan kedepan diarahkan pada peningkatan upaya promotif dan preventif dengan tidak mengesampingkan kuratif dan rehabilitatif. Salah satunya adalah upaya yang dilakukan memberikan edukasi tentang bagaimana cara mempraktikan perilaku hidup bersih dan sehat ( PHBS) kepada generasi muda.

\section{Penyuluhan kesehatan}

Penyuluhan kesehatan dilakukan di masyarakat dan di sekolah. Hal ini bertujuan agar masyarakat bertambah pengetahuannya tentang kesehatan dan mau meningkatkan kepedulian tentang kesehatan dirinya sendiri maupun oranglain. Berbagai upaya yang dilakukan seperti sosialisasi tentang kesehatan maupun pengadaan poster tentang kesehatandi sekolah. Hal ini dikarenakan sekolah belum memiliki media yang dapat menginformasikan kesehatan kepada peserta didiknya. Poster diharapkan dapat menginformasikan tentang kesehatan dan mudah pahami oleh semua umur agar informasi kesehatan yang disampaikan mampu menarik siapapun yang melihat akan tertarik untuk menerapkannya.

Selain itu poster juga diberikan diposyandu, dengan harapan poster tersebut bias menjadi media promosi kesehatan oleh bidan maupun kader posyandu, agar masyarakat sekitar bisa mendapatinormasi melalui gambar tersebut, sehingga posyandu dapat menjadi sumber informasi kesehatan bagi masyarakat.

\section{Penyegaran Kader Posyandu}

Posyandu merupakan perpanjangan tangan puskesmas yang memberikan pelayanan dan pemantauan kesehatan yang dilaksanakan secara terpadu.Kegiatan dalam posyandu meliputi pelayanan imunisasi, pendidikan gizi masyarakat serta pelayanan kesehatan ibu dan anak.Dalam posyandu terdapat kader-kader posyandu.Menurut Depkes RI (2003) Kader posyandu adalah anggota masyarakat, mau dan mampu bekerja bersama dalam berbagai kegiatan kemasyarakatan secara sukarela.Kader posyandu merupakan pilar utama penggerak 
pembangunan khususnya dibidang kesehatan.Karena kader posyandu merupakan pilar utama, sehingga mereka haruslah memiliki banyak pengetahuan dan keterampilan agar kegiatan pelayanan kesehatan dapat berjalan dengan baik.

Program kerja ini dilaksanakan dengan tujuan agar masing-masing kader kesehatan yang ada di posyandu mendapat pengetahuan dan wawasan lebih dalam bidang pelayanan kesehatan masyarakat. Selain itu program ini juga merupakan usaha untuk memupuk semangat kader agar tetap prima dalam melayani masyarakat di bidang kesehatan.Diharapkan agar nantinya kader posyandu dapat lebih terampil dan memiliki pengetahuan yang luas.Pengetahuan tersebut tidak hanya berasal dari bidan desa, melainkan bisa juga dari sumber-sumber lain dan dengan adanya kegiatan penyegaran ini, maka kegiatan di posyandu menjadi lebih berkembang dan bervariasi demi lancarnya kegiatan pelayanan kesehatan desa.

\section{Sosialisasi Cuci Tangan Menggunakan Sabun}

Program kerja ini dilaksanakan dengan tujuan agar para siswa/i sekolah dasar sederajat khususnya mengerti tata cara melakukan cuci tangan dengan baik dan benar, yang nantinya akan berdampak pada anak-anak tersebut, dan juga mengerti dan memahami pentingnya cuci tangan dalam kehidupan sehari-sehari yang berpengaruh pada kesehatan pada anak-anak. Setelah kegiatan ini diharapkan merka dapat mengerti dan memahami serta menerapkan langkah-langkah cuci tangan yang baik dan benar dan membiasakan untuk mencuci tangan sebelum makan dan sebelum tidur serta mencuci tangan setelah melakukan aktifitas

\section{Sosialisasi cara menyikat gigi yang baik dan benar}

Anak-anak sangat rentang terkena gangguan pada kesehatan gigi dan mulut yang di sebabkan karena faktor makanan yang di konsumsi, sikat gigi yang tidak teratur dan kurang benar, atau kurangnya perhatian orang tua terhadap kesehatan mulut anaknya.Melalui kegiatan ini, diharapkan siswa/i dapat mengetahui sekaligus mempraktikkan cara menyikat gigi yang baik dan benar dalam kehidupan sehari-hari, serta dapat menegtahui manfaat rutin menyikat gigi, sehingga mereka tidak akan malas-malasan lagi untuk menyikat gigi. Bila mereka rajin menyikat gigi, maka dapat mencegah penyakit yang mungkin akan timbul.

\section{Pemeriksaan Kesehatan}

Kegiatan ini dilaksanakan dengan tujuan untuk mendeteksi sedari dini jika ada masalah kesehatan sehingga jika dapat diketahui lebih awal diharapkan dapat dilakukan upaya pencegahan sehingga kejadian atau resiko keberlanjutan penyakit bisa diminimalisir atau bahkan dihilangkan.Kegiatan ini terdiri dari pemerikaan status gizi, pemeriksaan kebersihan diri, pemeriksaan mata, pemeriksaan telinga, pemeriksaan gigi dan mulut, serta pemeriksaan kebugaran jasmani.

Dari kegiatan ini diperolehlah data penjaringan kesehatan siswa sekolah dasar sederajat yang meningkat dari tahun sebelumya dari $29,1 \%$ menjadi $93,3 \%$.

\section{KESIMPULAN DAN SARAN}

\section{Kesimpulan}

Upaya peningkatan cakupan penjaringan kesehatan anak sekolah siswa SD sederajat sudah mengalami peningkatan dari sebelumya, dengan adanya pengenalan serta kegiatan-kegiatan yang positif merupakan upaya yang dilakukan guna mendukung program Kementrian Kesehatan "Keluarga Sehat untuk mewujudkan Indonesia Sehat 2020" dengan anak yang 
sehat diharapkan akan lahir generasi-generasi penerus bangsa yang cerdas, unggul dan kreatif. Hasil yang diperoleh dari kegiatanKKN-PPM ini anatara lain:

- Tersosialisasi materi-materi tentang kesehatan, prilaku hidup bersih dan sehat, serta penyakit-penyakit seperti DBD, diare dll.

- Terlatihnya kader kesehatan disekolah yang terdiri dari siswa sebagai dokter kecil dan guru sebagai penanggung jawab UKS.

- Bertambahnya keaktifan kader posyandu

- Meningkatnya data penjaringan kesehatan menjadi 93,3\%

- Diperolehnya Media Promosi (buku saku, Leaflet, poster \& banner)

\section{Saran}

Kegiatan seperti ini masih perlu untuk ditingkatkan lagi karena dapat membantu pihak mitra dalam meningkatkan cakupan penjaringan kesehatan siswa sd sederajat dan dapat memotivasi masyarakat desa tentang prilaku hidup sehat dan memahami pentingnya pemeriksaan kesehatan sedini mungkin.

Perlunya kegiatan lanjutan yang bertujuan untuk melihat sejauh mana budaya hidup bersih dan sehat sudah tertanam pada setiap siswa SD sederajat, sehingga diharapkan generasi penerus bangsa memiliki kebiasaan hidup bersih dan sehat.

Dalam merealisasikan semua program intinya diperlukan kerjasama.Bentuk kerjasama ini bisa diwujudkan jika adanya komunikasi yang baik antara masyarakat dan mahasiswa yang menjalankan program. Selain itu dibutuhkannya pendekatan-pendekatan yang bisa menarik simpati masyarakat sebagai sasaran program

\section{DAFTAR PUSTAKA}

Azwar Azrul. 2010. Pengantar Administrasi Kesehatan, Edisi ketiga. Binarupa Aksara. Jakarta.

Departemen Kesehatan RI. 2008. Pedoman Pelatihan Kader Kesehatandi Sekolah, Departemen Kesehatan,Jakarta.

Departemen Kesehatan RI. 2010. Panduan Perilaku Hidup Bersih Dan Sehat Di Rumah Tangga. Pusat Promosi Kesehatan Departemen Kesehatan. Jakarta.

Direktorat Bina Kesehatan Anak. 2010. Petunjuk Teknis Penjaringan Kesehatan AnakSekolah Dasar, Direktorat Jenderal Bina Kesehatan Masyarakat Kemenkes. Jakarta.

Direktorat Bina Kesehatan Anak. 2011. Modul Pelatihan Penjaringan KesehatanPeserta Didik. Kementrian Kesehatan RI. Jakarta.

Direktorat Bina Kesehatan Anak. 2011. Pedoman Untuk Tenaga KesehatanUsahaKesehatan Sekolah Di Tingkat Sekolah Dasar, Sekolah Menengah dan Pondok Pesantren. Direktorat Jenderal Bina Gizi dan Kesehatan Ibu dan Anak KementrianKesehatan RI. Jakarta. 